\title{
Impact of native forest restoration on endemic crickets and katydids density in Rodrigues island
}

\author{
Sylvain Hugel
}

Received: 3 October 2011/Accepted: 28 February 2012/Published online: 15 March 2012

(C) Springer Science+Business Media B.V. 2012

\begin{abstract}
Native species of oceanic islands are often unique and of conservation concern. Native habitat restoration schemes are now conducted on many oceanic islands, and are often characterized by both the small sizes of the restored areas, and the high degradation level prior to restoration. Whereas arthropods are often neglected in restoration schemes, on small tropical islands they may represent the largest proportion of extant native terrestrial animals surviving habitat degradation. The island of Rodrigues, in the South Western Indian Ocean, is typical of such cases. The only patches of forest and bushes remaining on Rodrigues in 1996 were dominated by nonnative invasive species. Since 1996, restoration schemes were conducted in Grande Montagne Nature Reserve. Benefits of these 15 years of native forest restoration were assessed on endemic Orthoptera density and diversity using acoustic monitoring and insect density measurements. Unrestored exotic plant-dominated areas were a low-density reservoir for endemic Orthoptera, many of which were new to science. Habitat restoration increased by four to seven times the density of these endemic Orthoptera, depending on the restoration scheme. The presence of managed areas did not significantly increase the density of endemic Orthoptera on the neighboring unrestored exotic plant-dominated areas.
\end{abstract}

Electronic supplementary material The online version of this article (doi:10.1007/s10841-012-9476-1) contains supplementary material, which is available to authorized users.

S. Hugel (两)

INCI UPR3212 CNRS, Université de Strasbourg, 21 rue René Descartes, 67084 Strasbourg Cedex, France

e-mail: hugels@inci-cnrs.unistra.fr
Keywords Orthoptera $\cdot$ Endemism $\cdot$ Acoustic monitoring · Inventory and monitoring $\cdot$ Mascarene

\section{Introduction}

The native flora and fauna of oceanic islands is often unique and characterized by high levels of endemism (Gillespie 2009; Kier et al. 2009). In most oceanic islands, anthropogenic factors such as habitat degradation/loss and invasive alien species introduction has caused species extinctions and threatened remaining ones (Kier et al. 2009; Kueffer et al. 2010). Native habitat restoration schemes are now conducted on many of these islands, and are often characterized by the small sizes of the restored areas and by high degradation levels prior to restoration (Caujape-Castells et al. 2010). Whereas many insect extinctions are taking place on islands, these animals are often neglected (Gillespie and Roderick 2002). However, they might represent most of extant native terrestrial animal species having survived habitat degradation.

Rodrigues is a small tropical island $\left(109 \mathrm{~km}^{2}\right)$ situated in the global biodiversity hotspot of the Malagasy area (South Western Indian Ocean). Rodrigues has been subjected to a dramatic destruction of its native habitats over most of its surface (Strahm 1993). The island has been almost entirely cleared for agriculture and firewood and the only patches of forest and bushes remaining before 1996 were strongly dominated by exotic invasive plants and were restricted to higher summits and deep valleys (Strahm 1993; Cheke and Hume 2008). These habitat losses forced the extinction of most native land vertebrates (Cheke and Hume 2008) and many endemic angiosperm species (Strahm 1993). Little is known on the entomofauna of Rodrigues, and only the extinction of conspicuous taxa 
such as a phasmid and a butterfly is documented (Viette 1995; Cliquennois 2007).

The first conservation efforts led in 1986 to the fencing of a 25.5 ha area at the top of a mountain named Grande Montagne, with 13.8 ha listed as a Nature Reserve (Strahm 1993; Payendee R., Waterstone A., Mauritian Wildlife Foundation (MWF), personal communication). Like the other similar summits of Rodrigues, Grande Montagne supported scattered native plants swamped by exotics. In 1996, an extensive restoration scheme was started in Grande Montagne, with gradual removal of exotics and planting of native seedlings grown in ex situ nurseries. Between 1996 and 2011 hundreds of thousands of native seedlings were planted in Grande Montagne, many of which are now flowering and fruiting, resulting in a gardened forest (Blanchard 2000) or a restored native forest (Cheke and Hume 2008).

While compiling the inventory of the orthopteroid fauna of Rodrigues (August 2001; April 2005; Febuary 2008; April 2010; April 2011), new Orthoptera species were discovered, mostly on Grande Montagne (Hugel 2012). Surprisingly, these species proved to be single-island endemics, increasing by three the number of known endemic Orthoptera occurring in Rodrigues.

These observations raised critical questions related to conservation. Are the areas dominated by exotic invasive plant species harboring endemic insects? Is the density of these endemic insects increased in restored areas? Is the proximity of restored areas increasing the density of endemic insects in exotic plant species-dominated areas?

\section{Methods}

Study areas (see also Online Resource 1)

The study was conducted in Rodrigues, an $18.3 \mathrm{~km}$ long by $8.5 \mathrm{~km}$ wide island $\left(63^{\circ} 25^{\prime} \mathrm{E} ; 19^{\circ} 43^{\prime} \mathrm{S}\right)$. Orthoptera density measurements were performed on four areas: two areas restored and managed since 1996 and two areas dominated by exotic plant species. The altitude of these four areas was similar, ranging from 360 to $393 \mathrm{~m}$. The plant cover of all four areas was similar until 1996, before restoration started, with Syzygium jambosa, Tabebuia heterophylla and Litsea glutinosa as dominating exotics (Strahm 1993; Strahm W. A., Payendee R., personal communication). The two areas managed since 1996 were localized in the upper part of Grande Montagne (GM), in GM Nature Reserve: one was managed by the Mauritian Wildlife Fundation (MWF), the other by the Forestry Service (FS). Both areas differed by the density of native seedlings planted: $\geq 4 \mathrm{~m}^{-2}$ in GMMWF-managed area; $\sim 1 \mathrm{~m}^{-2}$ in GM-FS-managed area. One of the two areas dominated by exotic plant species was in the upper part of Grande Montagne, in contact with the GM-MWF-managed area; the other was at the top of Mont Limon, a mountain surrounded by cleared areas, 1,800 m away from Grande Montagne.

Orthoptera from Rodrigues (see also Online Resource 2)

Recent field work on Rodrigues has recorded 22 Orthoptera species, most of which are widespread in the Malagasy Region, and seven of which are single-island endemics (Hugel 2010, 2012, SH unpublished data, Online Resource 2). Most of these endemic species are as yet undescribed and will be named elsewhere. Apart from the katydid Rodriguesiophisis spinifera (Butler 1876), all other endemic species are Trigonidiinae and Mogoplistidae crickets belonging to small radiations ( $\mathrm{SH}$ unpublished data). All are strictly arboreal and polyphagous.

Orthoptera acoustic monitoring (see also Online Resource 3)

Acoustic monitoring can give accurate assessment of singing insect density (Riede 1998). In Rodrigues, only two endemic Orthoptera species (Ornebius spl and sp2) are able to stridulate in the audible range, each species singing within distinct frequency windows that were used for the analysis. Global sound recordings were performed in two areas: GM-MWF-managed area and Mont Limon (dominated by exotic plant species) during both day (30 recording points per station in 2008 and 2011) and night (10 recording points per station in 2011). Recording points were at least $10 \mathrm{~m}$ apart, on the main path of both the GMMWF-managed area and in Mont Limon's upper part. At each recording point, ambient sounds were recorded during 2 min with an Audiotechnica AT822 microphone, on a HDRHC1E Sony camcorder. The continuous song and the high density of singers of both species resulted in a continuous background sound where single sources could not be distinguished. The density of singers was therefore assessed by analyzing the background sound power spectral density in the frequency windows of each species stridulation (determined by ex situ studio recordings).

Orthoptera density measurement

The status of both endemic flora and fauna on Rodrigues is too critical and the size of the restored areas is too small to allow the use of invasive monitoring methods such as traps or fogging. Non-invasive techniques were therefore used (standardized beating and acoustic monitoring) to monitor Orthoptera. In Grande Montagne plateau and Mont Limon's upper-part, the "canopy" reached the average height 
of $\sim 3 \mathrm{~m}$ in 2011 , allowing the use of beating- to evaluate the density of endemic Orthoptera. In the four sampled areas, the average height of bushes/trees shaken was similar (one-way ANOVA, $\mathrm{F}_{3,197}=0.382, p=0.766$ ). The use of beating was also possible as endemic Orthoptera are very poor flyers, at most able to glide. This density was evaluated by shaking the branches covering a $1 \mathrm{~m}^{2}$ circular sheet placed $<1 \mathrm{~m}$ under the branches. Branches were vigorously shaken during $10 \mathrm{~s}$ (at $2 \mathrm{~Hz}$ ). Specimens were directly identified, counted and released. Only two exotic arboreal katydid species were collected; these were excluded from the analysis. Bating sample locations were along transects with 5 point at least $5 \mathrm{~m}$ apart along each transect, which was positioned at random. In each sampling location, at least 50 beating points were assayed.

\section{Statistical analysis}

Differences in the power spectra integral in the frequency peak range of each species were assayed with unpaired Student's $t$ test. Differences in the number of endemic Orthoptera specimens and species per beating point for all 4 stations were assayed with a one-way ANOVA followed by Tukey-Kramer's post hoc multiple comparison test. Statistical analyses were performed using KyPlot 2.15 (Koichi Yoshioka, Japan).

\section{Results and discussion}

While compiling the Orthoptera inventory in Rodrigues, single island endemic Orthoptera were mostly found in restored areas of Grande Montagne, managed since 1996.

Our first objective was to determine whether areas dominated by exotic invasive plant species were acting as a low density reservoir for endemic insect species, and whether native forest restoration improved the density of these endemic insects.

Therefore, using an acoustic monitoring approach we compared the amount of singing Orthoptera in two independent stations: GM-MWF-managed area where the native forest has been restored, and an exotic-plant dominated area (Mont Limon) that was similar to GM-MWFmanaged area before restoration. Only two endemic Orthoptera species were singing in the audible range (Ornebius sp1 and sp2). Both Ornebius species were detected in both Mont Limon and Grande Montagne (Online Resource 4). The energy of the background sound caused by Ornebius sp1 was 37 times larger by day in Grande Montagne than in Mont Limon and 115 times by night (unpaired Student's $t$ test; $\mathrm{t}_{58}=3.19, p=0.002$, by day; $\mathrm{t}_{18}=4.26, p=0.0005$, by night, Fig. 1 ). Similarly, the energy of the background sound caused by Ornebius sp2 was 5 times larger by day in Grande Montagne than in Mont Limon and 4 times by night $\left(\mathrm{t}_{58}=2.06, p=0.045\right.$, by day, and $\mathrm{t}_{18}=2.33, p=0.032$ by night, Fig. 1 ).

We assessed directly the density of endemic Orthoptera with standardized beating in four areas: Mont Limon; GMMWF-managed area; GM-FS-managed area; the exotic plant-dominated area contacting GM-MWF-managed area (Fig. 2, Online Resource 5). The average density of endemic Orthoptera specimens measured by the beating method was of $1.46 \pm 0.19$ specimens $\mathrm{m}^{-2}$ in Mont Limon, confirming that endemic Orthoptera were present at low-density in exotic plant species-dominated area. This density was seven times larger in the GM-MWF-managed area where it reached $10.31 \pm 1.14$ specimens $\mathrm{m}^{-2}$ (TukeyKrammer post hoc test, $p=1.63 \times 10^{-6}$, Fig. 2a). As for specimen density, the density of endemic species was 2.31 times larger in the GM-MWF-managed area compared to Mont Limon $\left(1.94 \pm 0.14\right.$ vs. $0.84 \pm 0.10$ species $\mathrm{m}^{-2}$ in GM-MWF-managed area and Mont Limon, respectively; $p=1.63 \times 10^{-6}$, Fig. 2b). One Trigonidiinae cricket was only found in the GM-MWF-managed area, but only rarely ( 3 specimens out of 51 beating points). These data indicate

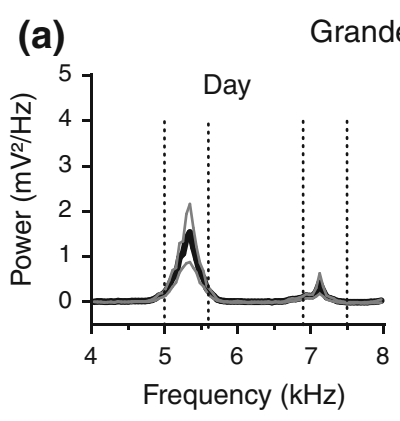
Grande Montagne

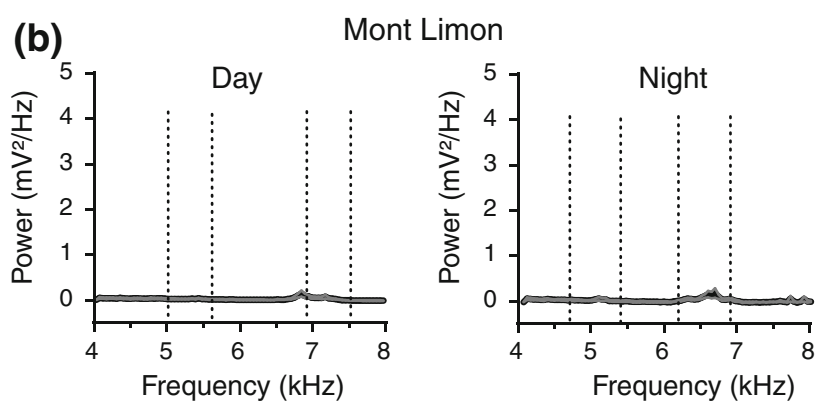

Fig. 1 Acoustic monitoring of endemic Ornebius cricket species in (a) the MWF-managed area of Grande Montagne, (b) the exotic plant species-dominated area of Mont Limon. The graphs illustrate the power of the recorded ambient sound as a function of the frequency. The black trace corresponds to the average, the thin grey traces correspond to the SEM $(\mathrm{n}=30$ for day recordings, $\mathrm{n}=10$ for night recordings, in both localities). The dotted lines indicate the frequency window analyzed for each species. Only few singing Ornebius males of both species were detected in Mont Limon whereas a loud continuous ambient sound was produced by these insects in MWFmanaged area of Grande Montagne. The day recordings were seldom contaminated by bird songs at $\sim 6.8 \mathrm{kHz}$ 

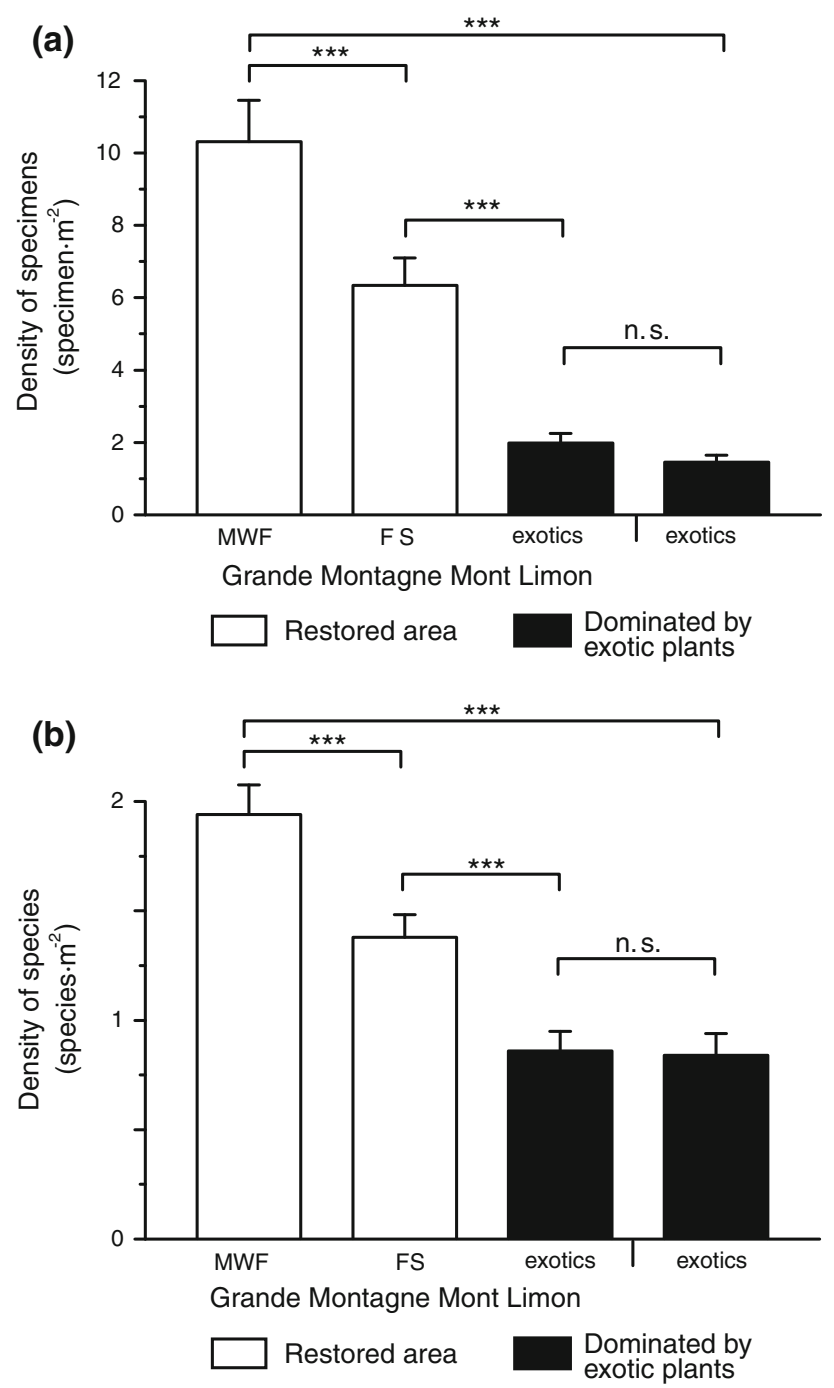

Fig. 2 Density of endemic Orthoptera (a) specimens and (b) species in two restored areas (open bars) and two areas dominated by exotic plant species (black bars). Both densities of specimens and species were significantly different (one-way ANOVA, $\mathrm{F}_{3,197}=34.333$, $p<0.0001$ for specimen density; $\mathrm{F}_{3,197}=23.058, p<0.0001$ for species density). The Mauritian Wildlife Foundation (MWF)-managed area of Grande Montagne was planted with $\geq 4$ native seedlings per $\mathrm{m}^{2}$. The Forestry Service (FS)-managed area of Grande Montagne was planted with $\sim 1$ native seedling per $\mathrm{m}^{2}$. The exotic plant species-dominated area of Grande Montagne is in direct contact with (MWF)-managed area. ${ }^{* * *} p<0.001$; n.s.: $p>0.05$ with TukeyKrammer post hoc test

that the density of endemic Orthoptera specimens and species was much greater in the restored native forest than in the exotic-plant dominated area. Importantly, these latter areas were not devoid of endemic Orthoptera. As both managed and unmanaged localities were similar before management, habitat restoration seems to have allowed the increase of endemic Orthoptera density. These insects could have spread from neighboring exotic plant-dominated areas playing the role of low-density reservoirs.
Although suboptimal for endemic Orthoptera, patches of exotic trees/bushes might have functionally replaced the native habitat of these insects that would most likely have been forced to extinction in a fully cleared island. Similar relative benefit of non-native plant patches has been reported in other cases (Rodriguez 2006; Kaiser-Bunbury et al. 2010) such as for the Rodrigues Warbler (Showler et al. 2002), an endangered passerine (BirdLife International 2000).

Distinct restoration schemes have been implemented in Grande Montagne, with distinct densities of native seedlings planted: $\geq 4 \mathrm{~m}^{-2}$ in the GM-MWF-managed area; $\sim 1 \mathrm{~m}^{-2}$ in the GM-FS-managed area. In the latter area, the average endemic Orthoptera density was of $6.34 \pm 0.76$ specimens $\mathrm{m}^{-2}$. This density was significantly larger than that measured in Mont Limon, an exotic-plant dominated area $\left(p=1.68 \times 10^{-5}\right.$, Fig. 2a), but was significantly smaller than that measured in the GM-MWF-managed area $(p=$ 0.0006 , Fig. $2 b$ ), indicating that the density of native seedlings had an impact on the density of these endemic insects. As for specimen density, the density of endemic Orthoptera species was 1.64 times larger in the GM-FS-managed area compared to Mont Limon $\left(1.38 \pm 0.10\right.$ species $\mathrm{m}^{-2}$ in GMFS-managed area; $p=0.003$, Fig. $2 b$ ) but this density was significantly smaller than that measured in GM-MWFmanaged area $(p=0.002$, Fig. $2 b)$. Importantly, in the $1 \mathrm{~m}^{-2}$ plant density area, native bushes and trees are only starting to be in contact with each other. This might be the reason for this difference, as these insect species are strictly arboreal and display limited ability to dispersion.

Finally, the possibility that the restored area was acting as a source of endemic insects to the neighboring exotic plantdominated area was addressed. The density of endemic Orthoptera in an exotic-plant dominated area directly contacting the GM-MWF-managed area was assessed using standardized beating. In this area, the average density of endemic Orthoptera was of $1.98 \pm 0.26$ specimens $\mathrm{m}^{-2}$. This value was not significantly different from that measured in Mont Limon, an exotic-plant dominated area ( $p=0.955$, Fig. 2a). As with the density of specimens, the density of endemic Orthoptera species was similar in the exotic-plant dominated area directly contacting the GM-MWF-managed area and in Mont Limon ( $p=0.999$, Fig. 2b). These data indicate that the direct contact of restored native forest has not improved the density of endemic Orthoptera in an exotic plant species-dominated area, suggesting that restored native forest does not have the role of a source for these insects. Nevertheless, this observation might be related to the relative size of both areas and the reduced mobility of these insects. Importantly, modeling suggests that extinction probability of a katydid population is lower in an optimal habitat with a surrounding suboptimal habitat than without (Griebeler and Gottschalk 2000), suggesting that the exotic plant-invaded 
areas surrounding the restored areas of Grande Montagne are of importance for the survival of endemic Orthoptera populations.

With up to 10 specimens per square meter, the density of endemic Orthoptera in the MWF-managed area of Grande Montagne is very high. This striking abundance in the restored native forest of Grande Montagne might be linked with the apparent spectacular recovery of the Rodrigues Warbler in this locality (Mauritian Wildlife Foundation 2008; Cheke and Hume 2008). Indeed, we observed this passerine feeding on endemic Orthoptera (Trigonidiinae, Mogoplistinae).

The native forest restoration conducted in Grande Montagne seems to have allowed a dramatic increase in the density of endemic Orthoptera, which might in turn have contributed to the apparent increase in Rodrigues Warbler's population in this locality. Thus, native habitat restoration may have facilitated the interaction of native species, a feature recently proposed as a biodiversity monitoring tool (Kaiser-Bunbury et al. 2010).

More than a gardened area, this suggests that Grande Montagne Nature Reserve may better be regarded as a restored native forest, leaving hope for restoration schemes of badly degraded areas on small tropical islands.

Acknowledgments We acknowledge the National Parks and Conservation Service, Rodrigues Regional Assembly and Forestry Service, and the MWF for having allowed and helped our investigations. We thank Richard Payendee, Arnaud Meunier and all the MWFRodrigues team for their enthusiastic assistance. We thank Vincent Florens, Owen Griffiths, Julian Hume, Jean-Luc Rodeau, Wendy Strahm, Vikash Tataya, Andrea Waterstone, for their help and our discussions. This work was partially funded by the BIOTAS project, ANR-06-BDIV-002.

\section{References}

BirdLife International (2000) Threatened birds of the world. BirdLife International, Cambridge, UK and Lynx Edtn, Barcelona

Blanchard F (2000) Guide des milieux naturels: La Réunion, Maurice. Rodrigues, Eugen Ulmer, Paris, France

Caujape-Castells J, Tye A, Crawford DJ, Santos-Guerra A, Sakai A, Beaver K, Lobin W, Florens FBV, Moura M, Jardim R, Gomes I,
Kueffer C (2010) Conservation of oceanic island floras:present and future global challenges. Perspect Plant Ecol Evol Syst 12:107-129

Cheke A, Hume J (2008) Lost land of the dodo. A \& C Black Publishers, London

Cliquennois N (2007) "Vivant, était vert avec des antennes rouges": extinction de Xenomaches incommodus, phasme endémique de l'île Rodrigues (Phasmatodea). Bull Soc Entomol Fr 112: 375-376

Gillespie RG (2009) Naivete and novel perturbations: conservation of native spiders on an oceanic island system. J Insect Conserv 3: 263-272

Gillespie RG, Roderick GK (2002) Arthropods on islands: evolution and conservation. Annu Rev Entomol 47:595-632

Griebeler EM, Gottschalk E (2000) An individual based model of the impact of suboptimal habitats on survival of the grey bush cricket, Platycleis albopunctata (Orthoptera: Tettigoniidae). J Insect Conserv 4:225-237

Hugel S (2010) New and little known predatory katydids from Mascarene islands (Ensifera, Meconematinae and Hexacentrinae). Zootaxa 2543:1-30

Hugel S (2012) Trigonidiinae crickets from Rodrigues island: from widespread pantropical species to critically endangered endemic species. Zootaxa 3191:41-55

Kaiser-Bunbury CN, Traveset A, Hansen DM (2010) Conservation and restoration of plant-animal mutualisms on oceanic islands. Perspect Plant Ecol Evol Syst 12:131-143

Kier G, Kreft H, Lee TM, Jetz W, Ibisch PL, Nowicki C, Mutke J, Barthlott W (2009) A global assessment of endemism and species richness across island and mainland regions. Proc Natl Acad Sci USA 106:9322-9327

Kueffer C, Daehler CC, Torres-Santana CW, Lavergne C, Meyer JY, Otto R, Silva L (2010) A global comparison of plant invasions on oceanic islands. Perspect Plant Ecol Evol Syst 12:145-161

Mauritian Wildlife Foundation (MWF) (2008) Annual report 2007/8. MWF, Mauritius

Riede K (1998) Acoustic monitoring of Orthoptera and its potential for conservation. J Insect Conserv 2:217-223

Rodriguez LF (2006) Can invasive species facilitate native species? Evidence of how, when, and why these impacts occur. Biol Invasions 8:927-939

Showler DA, Côté IM, Jones CG (2002) Population census and habitat use of Rodrigues Warbler Acrocephalus rodericanus. Bird Conserv Int 12:211-230

Strahm WA (1993) The conservation and restoration of the flora of Mauritius and Rodrigues. PhD thesis. University of Reading, Reading, UK

Viette P (1995) Notes sur quelques espèces de Rhopalocères de l'archipel des Mascareignes appartenant aux genres Antanartia, Salamis, Danaus et Euploea (Lepidoptera Nymphalidae). Bull Soc Entomol Fr 99:517-524 